\title{
Satisfaction Level of Athletes Regarding Sports Facilities at Collage Level in Bahawalpur Pakistan
}

\author{
Muhammad Zahid Mahmood \\ S.S. Physical Education Workers Welfare Higher Secondary School Multan. \\ Email: jatala113@gmail.com
}

Amira Farooq EST Government Girls Elementary School Chak No 139/DB Bahawalpur. Email: ac32047163@gmail.com

\author{
Misbah Ashraf \\ EST Government Girls High School Dehlra Narowal. \\ Email: misbaha.ashraf@gmail.com
}

Received on: 01-10-2021

Accepted on: 02-11-2021

\begin{abstract}
The main objectives of the study were to examine the influence of internal and external factors on the satisfaction level of athletes and to find out the most dominant factors affecting college sports in Government and private colleges in Bahawalpur District, Pakistan. The researcher created 10 hypotheses to examine the objectives of the study. Male and female athletes, government, and private college controlled sport were selected as part of the study. A 20\% representative sample was taken from both male and female athletes, but the total population consisting of sports directors from both colleges was taken according to the Gay formula (1985). A representative sample of 100 was selected using a convenient sampling method. A self-development questionnaire was used to collect data. The validation process, test cases and reliability were performed accordingly. The questionnaire was personally distributed to all respondents. The returned responses were analyzed using SPSS version 20 and Excel Micro software. In the first step, the researcher used descriptive statistics that showed the frequency, percentages and averages of the responses. Second, the researcher used unpredictable statistics to examine formulation hypotheses. The results of the study were drawn based on the analysis of the data. The data showed that all internal and external factors are in both --colleges and have had a significant impact on the athletic satisfaction of athletes in Bahawalpur -- colleges in Pakistan (P> 0.05). However, the impact of all internal and external factors was found to be greater in private colleges compared to Government College. Regarding dominant factors among internal and external factors, both in public and private colleges, it was concluded that inappropriate training and participation of athlete training dominated internal factors and family influence among external factors affecting sport at both colleges in Bahawalpur district, Pakistan. It is recommended that the relevant
\end{abstract}


Vol. II, Issue 3, Oct - December 2021

ISSN No: (ONLINE): 2710-043

www.irjei.com
International Research Journal of Education and Innovation

ISSN No: ISSN (PRINT): 2710-0448

DOI: https://doi.org/10.53575/irjei.v2.03(21)1.1-14

\section{Satisfaction Level of Athletes Regarding Sports Facilities at Collage Level in Bahawalpur}

authorities should provide all facilities for athletes to increase student participation in sporting activities at college level.

Keywords: Satisfaction, Athlete, Sports, Facilities

\section{INTRODUCTION}

\subsection{Background of The Study}

Sport is a global activity and can be seen in the sky, in the desert, on the plane, on the surface and in the mountains. The role of sport is universal and covers many aspects of human life. Its role is multidimensional. In addressing physical and health problems, it serves as a medical tool in the rehabilitation process and treats a range of physical, mental, emotional, psychological and social ailments. Researchers around the world have conducted various studies on the role of sport in promoting human health and improving lifestyle. Lidor, Melnik, Bilkevitz, Arnon, and Falk (2005) concluded that sporting activities have special codes of conduct that develop punctuality, obedience, respect, care for the opponent and obedience to rules and regulations.

They also found that these positive emotions encourage and attract the community to share these benefits of participating in sports through active participation in games. Participation in sports is one of the prerequisites for maintaining and strengthening the mental and physical well-being of the participant as it contributes to development, character development, relief and entertainment from everyday stress. According to Ekuri, Edim, and Odok, (2014) Sport and development are related because development is a period in which a person develops his character and learns how to deal with situations such as stress to record the journey of life. According to Wang, Lan and Wong (2001), participation in sports helps to control a person while interacting with others and emergencies that improve the quality of social life.

Immediately, Pakistan's performance at the global level has been at its lowest ebb. In light of Geo News (2016), Pakistan's Olympic contingent performed poorly at the Rio Olympics 2016 in Brazil. The channel added that the country has a population of over approximately 200.96 million, with only a small number of competitors, seven athletes competing in the Rio Olympics and none of them coming close to victory. Let us look at the performance of Pakistani players one by one. Najma Parveen finished 70th out of 72 participants in the $200 \mathrm{~m}$ race and the only hope for any distinction at the Rio Olympics was defeated by Shah Hussain Shah by a Ukrainian athlete in the second round of the judo competition. Similarly, Minhal Sohail won 28th position out of 52 participants in the women's shooting competition, and in freestyle swimming, both Haris Bande and Liana Swann took part and finished 50th out of 50 participants and finished 64th. In addition, another disappointing performance was recorded when Mehboob Ali was ranked 46th out of 53 athletes in the $400 \mathrm{~m}$ race and according to him shooter Ghulam Mati Bashir even reached the finals of the $25 \mathrm{~m}$ Rapid Fire Pistol Competition at the Rio Olympics. In hockey, Pakistan's national sport, we set a new record by not qualifying for the Rio Olympics 2016. Moreover, most importantly, it is important to point out that Pakistan has not won any Olympic medal.

Given the above statistics, it can be claimed that the college is one of the most important institutions in other countries for the development of athletes who represent their country in international sports competitions. Nevertheless, the level of participation of students in 
Vol. II, Issue 3, Oct - December 2021

ISSN No: (ONLINE): 2710-043

www.irjei.com
International Research Journal of Education and Innovation

ISSN No: ISSN (PRINT): 2710-0448

DOI: https://doi.org/10.53575/irjei.v2.03(21)1.1-14

Satisfaction Level of Athletes Regarding Sports Facilities at Collage Level in Bahawalpur

sports activities in Pakistan is much lower than other countries and they do not give much importance to sports activities at the college level. In Pakistan, they may have some factors that limit sports participation in college and the production of national and international athletes.

In this chapter, we discuss the sports facility satisfaction on college level. Firstly, we discuss what the sports and importance of sorts. Sports facilities to promote our students engagement in any kind of sports activities are of great importance for our college. Much importance is given to winter sports because the region is one of the most important winter sports centers. Students and trainers who have an interest in skiing and running can make good use of the facilities nearby. Institution and campus lifestyles are major factors in determining what recreational sport facilities exist on college or college campuses. Varsity sports, intramural sports, and recreational activities are important elements of campus lifestyle, which has an impact on facilities. Reflecting on institutional and campus lifestyle may guide the development of recreation sport facilities. This study was concerned with the ways in which recreational sports facilities reflect the campus culture of institutions and affect social interaction among college students. When people think about their college experience, they think about more than just courses, professors, and textbooks (Antonio, 2011).

Games and sports are an integral part of a student's life. A student should study hard to be successful in competitive examinations. However, he should also play games and sports to enjoy the health and vigor of life. Along with bookish learning, a student should spend his time on games and sports. Many people give importance only to bookish knowledge. Indeed, there is often no provision for games at all. Sports an activity involving physical exertion and skill in which an individual or team competes against another or others for entertainment. Sport forms an aspect of physical education. They are activities done for enjoyment during leisure hours and they involve competition. Some sports are done individually, or with a partner such as swimming, running, jumping, throwing, cycling, lawn tennis, table tennis, badminton and squash. Other sports are done in teams such as soccer, volleyballs, among others. All sports have their rules, which players must obey. Sport can then be defined as any activity that is completive in nature and must have recorded history of development, rules and regulations involving physical exertions and organized associations such as squash, rackets, soccer, and hockey. Sport facilities therefore connote permanent structures built for the sporting activities such as Athletic tack, stadia, soccer pitches, basketball court, lawn tennis courts, squash court, gymnasium, among others. Sport equipment on the other hand refers to those disposable items used in sports such as horizontal bars, weight lifting materials, basketball posts, hockey post, among others.

One of the most important areas of administrative concern of the sports administrators involves the management of facilities and equipment in physical education and sport programmers. The existence of sports facilities and equipment is of vital importance in the conduct of physical education, intramural sports and other sport programs. The facilities and equipment available in a college for the conduct of sports and games programs determine to considerable extent the type of sports programs that can be offered (Bargchi, 2010).

Young people spend a significant amount of time at college and therefore college environments need to be supportive of student being physically active. College sport and 
physical education programs are important and need a comprehensive approach for providing this support. Numerous studies have pointed out that college sport is an important aspect of philosophy of education and should operate within the overall policies. Sports can play a vital role in molding the charter of any nation and for a healthy and peaceful society. The first and the most important cause are differences created in our society. In our country, the worst thing is that we do not take sports seriously and think that it is waste less but in my view if our government will start giving attention for promoting sports at national and domestic level so we could control crime and other anti-social activities in which our new generation is taking interest. However, sport facilities and equipment in many universities are poorly managed. Some college does not have it at all. Physical educators and sport administrators do not give proper management and maintenance to these facilities at all. This has greatly hampered and reduced sport practices in the college. Students are not lack in talent but the dilemma is that Students do not take sports as necessary thing.

The only solution is that Students should start giving priorities to our talent and Students should not underestimate them. At government level, steps should be taken for promoting football talent; academies should be formed in which the young generation can get the chance of grooming at low cost or without cost. Special attention should be given to football talent in Layari and football academy with all the facilities should be formed so that our coming generation can find the place for grooming their talent. If government will start promoting sports at domestic and national level and allocate special funds for promotion of sports facilities so that day is not so far when Pakistan can make a make in sports all around the world (Feng, 2008).

\subsection{Statement of the Problem}

Sport facilities and equipment are compulsory for any college that is offering physical education. Their presence in the college can enhance physical education and intramural sports. Sport facilities and equipment therefore need proper management for effective use and long lasting. Having them without proper management and maintenance is like not having them at all. The management of sport facilities and equipment is the responsibility of physical educators and sport administrators at all levels.

In Pakistan, student participation in college-level sports does not give the impression in the connecting space of providing these kinds of competitors to talk about their country on a national level and international sport competitions as different countries. The close investigation was an effort in light of the aforementioned reason. The researcher intended to know the influencing factors both in government and private sector colleges of Bahawalpur, Pakistan responsible for low participation in sport activities.

However, the researcher was also inclined to influence the more prevalent factors that influence college sports. The survey correlates to show the impact of sports interpreterrelated components at private and government colleges. The researcher chose some of the significant angles identified with college sport as the impact factor that influences the level of support of the competitors. The specialist has divided these points of view into two main factors, for example internal factors and external factors. Internal factors included emergency care (first aid), coaching and preparation, motivation for competitors, enthusiasm among 
Satisfaction Level of Athletes Regarding Sports Facilities at Collage Level in Bahawalpur

college authorities, sports bureaus, and scientific engagement in research regarding sports. External factors also included the function of the media, legal circumstances, impact on the family and socio-cultural restrictions. The analyst, in addition to influencing the correlation between state and private colleges in terms of components, also included the selected population segment of the two divisions of the colleges of Bahawalpur Pakistan. In addition to comparing public and private sector colleges in terms of influencing factors, the researcher also compared the two sector colleges of Bahawalpur Pakistan with the demographic characteristics of the selected population.

\section{LITERATURE REVIEW}

This chapter deals with the review of related literature under various sub-headings such as concept of sports, sport facilities and equipment, care and maintenance of sports facilities and equipment, management and supervision of facilities and equipment, problems of poor maintenance of sport facilities and equipment and suggestions for proper management of sport facilities and equipment.

In this chapter, the researcher tried to highlight all the aspects with the help of the literature selected for this research study. Initially, the researcher sought to gather the perspectives of various researchers on the positive contribution of sports activities to an individual's life. Upon completion of this section, the researcher divided the rest of the literature into two main sections, namely, internal factors and external factors influencing college sports. Internal factors were further subdivided into six smaller factors, such as

(a) First aid

(b) Coaching and training

(c) Athletic motivation

(d) College sports interest

(e) Sports facilities

(f) Academic pursuits Students were similarly divided into external factors into four smaller factors, such as (a) the role of the media (b) the law and order situation (c) family influence (d) the extent of social culture. Therefore, in this chapter, the researcher focuses on two important areas (internal factors, and external factors) to develop a literature with the help of another study conducted before this study.

\subsection{Significance of Study}

The findings of this study will be significant in the following ways:

It will help to enlighten the sport administrators and physical educators. Since college plays a major role in providing individuals in the community who strive to develop all aspects of society. In sports, colleges play a major role in preparing the elite players. The current study is important because it identified some of the main factors that impeded college play.

This study helped demonstrate the athletes' academic involvement in internal factors such as first aid, training, coaching, and incentives for athletes, college management interest, sports facilities, and organized sporting activities at college level. This study will help in discovering the influence of external factors such as the role of the media, the status of law and order. This study sheds light on the perspectives of athletes, and sport managers on the effects of various internal and external factors on college sports. This study will provide the 
Satisfaction Level of Athletes Regarding Sports Facilities at Collage Level in Bahawalpur

public with information on the most powerful factor in college sport that may be responsible for the decline in college sports activities in Bahawalpur, Pakistan. Moreover, draw the public / authorities' attention. No doubt, drawing the attention of stakeholders to overcome the aspects and promote the positive, highlighting its research studies can help in the development of college sports.

\subsection{Internal Factors}

Internal factors refer to each of those variables that affect college sports exercises among competitors. For example

(A) First aid

(B) Consulting and training

(C) Incentives for athletes

(D) The interest of college players

(E) Sports facilities

(F) Academic participation of students

\subsection{External Factors}

Extrinsic variables refer to items created from a perspective external to college conditions, e.g., (a) function of media (b) law and conditions of demand (c) influence of family (d) restriction of social culture. Following the variations mentioned above, they are individually examined in the same way.

Sports facilities are not just for apartment complexes, community recreation centers, and hotels. Another popular place to find them is on the campus of a college or state college. Oncampus facilities also benefit college and universities in countless ways and make a huge impact on the communities around them. The truth is, if academic institutions have a sports facility on campus and promote it well, students and faculty will take advantage of its convenience. Moreover, more active students and faculty means healthier lifestyles for everyone. Having a sports facility within walking distance of the dormitories and other common areas will encourage students and faculty to be more active, engage in team sports with their peers, and attend intramural games on campus (Feng, 2008).

Moreover, the sports facilities on campuses of college and universities also allow for event hosting of other types. Whether it's an indoor fair, a high school game, or a college club event, sports facilities are much more than just a place to work out or play basketball they are also multi-purpose spaces that can be repurposed as needed. Students and visitors are more likely to choose a college or college that provides amenities such as an on-campus sports facility. Being able to provide sports facilities for students and community members also shows a diligence and dedication on your part, emphasizing the fact that you want students to be happy and healthy. Sports facilities can truly expand opportunities, affect the on-campus culture, and encourage healthy habits on a college campus. Sometimes, cultural differences can cause some problems in community relations and in workplaces. Participating in-group activities can help to increase cohesion in both the community and the workplace. Sports tourism also brings more cultural diversity to many types of different events. Sports facilities can hold large tournaments that can bring people from neighboring towns and villages. This increase of people can help bring more revenue into the town or village a few times a year. 
Vol. II, Issue 3, Oct - December 2021

ISSN No: (ONLINE): 2710-043

www.irjei.com
International Research Journal of Education and Innovation

ISSN No: ISSN (PRINT): 2710-0448

DOI: https://doi.org/10.53575/irjei.v2.03(21)1.1-14

Satisfaction Level of Athletes Regarding Sports Facilities at Collage Level in Bahawalpur

Local businesses can also see an increase in revenue during these large events (Bogar, 2012). Higher education is widely considered as a part of service industry since the orientation of its institutions is to provide quality services to students in an increasing competitive environment (Yeo, 2008). In this respect, meeting students' needs and expectations come into prominence to attract and retain quality students (Elliott \& Shin, 2002). The evaluation of the student experience can be divided into two approaches. The first approach involves methods with an emphasis on evaluating teaching and learning, while the second approach deals with methods that evaluate the total student experience (Aldridge \& Rowley, 1998). When students are considered as consumers of higher education, their level of satisfaction plays a relatively important role for institutional success in terms of effectiveness and recruitment (Thomas \& Galambos, 2004). Student satisfaction is adopted as a short-term attitude resulting from an evaluation of students' educational experience and student life is a web of interconnected experiences that affects student satisfaction (Elliott \& Healy, 2001). A satisfied student population is considered as a source of competitive advantage with several advantageous outcomes involving student retention and loyalty (Arambewela \& Hall, 2009). Every higher education institution has an important process such that the retention of students within the college campus until the end of their career which is closely related to the satisfaction with service experience (Cardona \& Bravo, 2012).

Anejo and Okwori (2004) state that, the existence of sport facilities is of vital importance in the conduct of physical education, intramural sports and other sport programs. They further say that, the facilities available in a college for the conduct of sports and games programs determine to a considerable extent the type of sports programed that can be offered.

In a related view, Ekanem (1995) observed that standard facilities are essential prerequisites to good and impressive performances in sports at all levels of participation. He further says different types of activities require different facilities. Consequently, therefore any limitation of these facilities creates difficulties in presenting the desired variety of sports activities.

\subsection{Management and Supervision Facilities}

Daft and Marcil (1998) refer to management as the attainment of organizational goals in an effective and efficient manner through planning, organizing, leading and controlling organizational resources. Dubrin, Ireland, and Williams (1989) define management as the coordinated and integrated process of utilizing an organization's resources (e.g. human, financial, physical, information/technological), to achieve specific objective through the functions of planning, organizing, leading, controlling, and staffing. Hersey and Blanchard (1982); Decenzo and Robbins (1999) note that management is working with and through individuals and groups to effectively accomplish organizational goals. Educational administrators (1955) have long described management as "the total of the processes through which appropriate human and material resources are made available and effective for accomplishing the purpose of an enterprise".

\subsection{Proper Equipment}

Facilities staff and coaches should also be responsible for making sure the proper equipment is available and in good working condition. Allowing players to use equipment that is not up 


\section{Satisfaction Level of Athletes Regarding Sports Facilities at Collage Level in Bahawalpur}

to par for safety can lead to injuries and accidents for which the facility and its staff will be responsible. The facilities management plan should monitor the equipment and check the procedures for getting equipment repaired and taken out of play. This plan should also include sanitizing where necessary. Sports facilities should have a facility management plan in place that reduces the risk for all involved in youth sports, from parents to custodians, coaches to spectators. When a solid plan is in place and everyone knows their role in reducing the risk, the chance of adverse outcomes decreases significantly

\subsection{Objectives of the Study:}

The study was based on the following objectives:

1. To investigate that the internal, external factors in the study influence athletes' satisfaction level

2. To examine the effect of external and internal factors influencing organized Sport program at government and private colleges Bahawalpur Pakistan.

3. To determine the relationship among different factors influencing Sport in government and private sector colleges of Bahawalpur Pakistan.

4. To determine the difference in the factors influencing organized Sport program at the government and private sector Colleges of Bahawalpur Pakistan.

\subsection{Research Questions}

The following are the research questions for the study:

What are the sport facilities and equipment in college sports?

What are the various ways of caring and maintaining sport facilities and equipment in college sports in the study area?

What is the task of physical educators and sport administrators in the management of sport facilities and equipment in college sports in the study area?

\subsection{Hypotheses of the Study}

Following hypotheses were formulated for this research study.

1. There is a significant effect of internal factors upon college Sport as perceived by the athletes and director sport of government sector colleges of Bahawalpur, Pakistan.

2. There is a significant effect of external factors upon College sport as perceived by the athletes and director sport of government sector colleges of Bahawalpur, Pakistan.

3. There is a significant effect of internal factors upon college sport as perceived by the athletes and director sport private sector colleges of Bahawalpur, Pakistan.

4. There is a significant effect of external factors upon college sport as perceived by the respondents of private sector colleges of Bahawalpur, Pakistan.

5. There no significant difference between the perception of government and private sector colleges respondents regarding the effect of internal factors upon college sport in Bahawalpur, Pakistan.

\section{METHODOLOGY}

The research method used is the theoretical investigation of the strategies applied in the field 
Satisfaction Level of Athletes Regarding Sports Facilities at Collage Level in Bahawalpur

of study. It includes a hypothetical examination and theoretical analysis of all the technologies and criteria linked to a piece of information. Usually ideas include, for example, worldview, theoretical model, quantitative or subjective phases and methods (Ishak and Alias, 2005). This section contains a diagram of the exploration technique used to explain specific discoveries were made and their accuracy. The main focal point of this specific exploratory study was to consider the inescapable elements affecting sport in public and private district colleges in Bahawalpur, Pakistan. This part of the survey briefly explains the screening plan, the audience, the strategy used to select the test and test size, the tools, their legality and reliability used to classify the information, the method of classifying the information and the information investigations.

\subsection{Research Design}

The present research has been designed to examine quantitative research based questions. The present study was proposed to be of descriptive type. It has quantitative aspect. Quantitative approach has been adopted for the questionnaire. A self-reported questionnaire was selected.

This study was exploratory and descriptive in nature. The Survey method was used to collect the necessary data from the respondents. Wyse (2012) asserts that the overview is generally modest and comprehensive because it helps present the characteristics of a very large population and the overview can be organized in several ways. The researcher further states that the method allows respondents to respond with greater legitimacy and generosity.

Descriptive research is a type of study that is primarily concerned with presenting the nature or conditions and degree of the present situation in detail. The aim of Descriptive research is to examine speculations and hypothesis clarifying the current situation in order to explain it (Jackson, 2009). Descriptive research is also known as Statistical Research. The main purpose of this investigation is to provide information and features about what is being investigated. Bear in mind the frequency, repetition, averages and other facts behind such research. The test of Descriptive research is mainly undertaken when an expert has to develop a higher understanding of a point. That is, analyzing the past rather than the futuristic things. Descriptive research is the exploration of the existing certain phenomena. The details of the facts will not be known. The existing phenomena's facts are not known to the person (Shields et al., 2006).

\subsection{Sample size and sampling technique}

Random sampling was used and a sample of 100 respondents was selected to collect the data. Out of total population of 100 students, 50 students were selected from the Sadiq Ejerton College and 50 students were selected from Government College Bahawalpur.

"A small part or a large number of any object, which is intended to express the whole quality, style or nature, is called a sample. In the data, the sample is described as a subset of the population. (Dictionary.com, 2017)

Table \#:

Options, Codes and Weight of Likert type scale

S. No Options Code Weight

1. Strongly Agree SA 5 
Vol. II, Issue 3, Oct - December 2021

ISSN No: (ONLINE): 2710-043

www.irjei.com
International Research Journal of Education and Innovation

ISSN No: ISSN (PRINT): 2710-0448

DOI: https://doi.org/10.53575/irjei.v2.03(21)1.1-14

Satisfaction Level of Athletes Regarding Sports Facilities at Collage Level in Bahawalpur

2. Agree A 4

3. Undecided UD 3

4. Disagree DA 2

5. Strongly Disagree SDA 1

\subsection{Conceptual Framework of the study}

The above framework shows a meaningful relationship between research variables where the idea of current research was comparative. Three variables types, such as independent variables, dependent variables and demographic variables make visible in the above figure. The independent variables were about internal and external factors, the subordinate factors were about the categorized play of government and private colleges, and the variables show the socioeconomics of the respondent, such as the organized sport and competitors for both the colleges in Pakistan.

The effect of independent factors on the dependent factors of government schools and the effect of independent variables on dependent variables in private colleges can be monitored. Moreover, the figure also highlighted the comparison between two types of colleges with reference to the influence of internal and external factors affecting organized sport in private and government sector colleges in Bahawalpur, Pakistan.
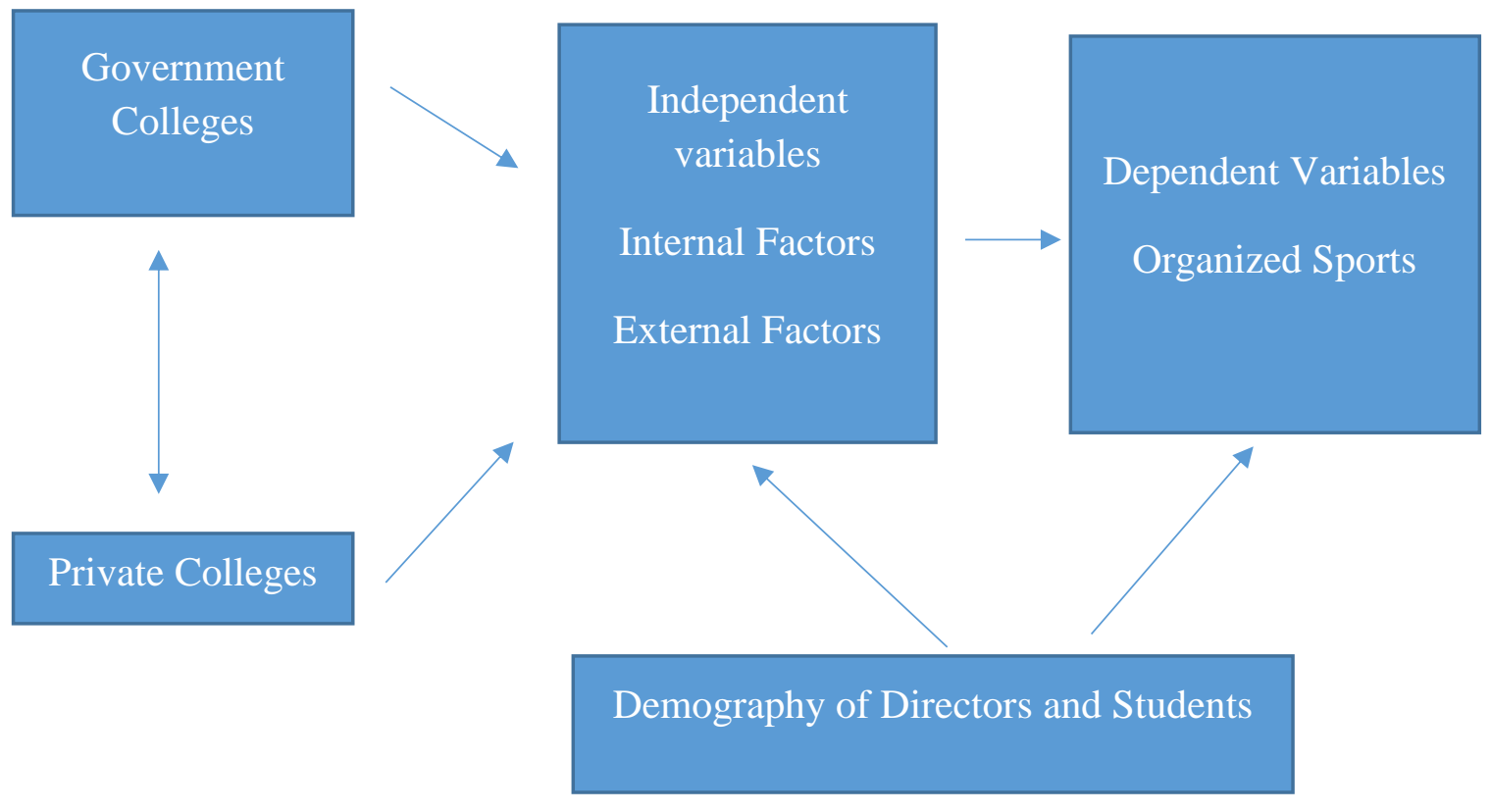

Fig: No. 3.1:

\section{DATA ANALYSIS}

The data collected from a well-organized questionnaire was run on database (SPSS and Microsoft Excel) for analysis procedure. Average reported frequency of responses of 


\section{Satisfaction Level of Athletes Regarding Sports Facilities at Collage Level in Bahawalpur}

questionnaire was analyzed. In order to find statistically significant connection was interpreted by tabulation and charts. The above stated chapter presented the methodology, which includes the research design, the instrument, the collection procedure and the data analysis. The next chapter provides data analysis and interpretations.

This specific section of the study deals with presentation and analysis of data. The main purpose of the study was to compare the factors affecting sport in the colleges of the public and private sectors in Bahawalpur Pakistan. The focus of the study was to assess the impact of internal factors. (First aid, training and training, incentives for athletes, interest of college authorities, sports facilities and academic participation of athletes), when practicing college sports. In addition, the study also focused on assessing the impact of external factors; (The role of the media, the state of law and order, the influence of the family and social and cultural restrictions), in college sports. Data were collected through Likert's questionnaire and analyzed in two different sections.

Table-4.1

I feel that college provides adequate sports equipment for athlete.

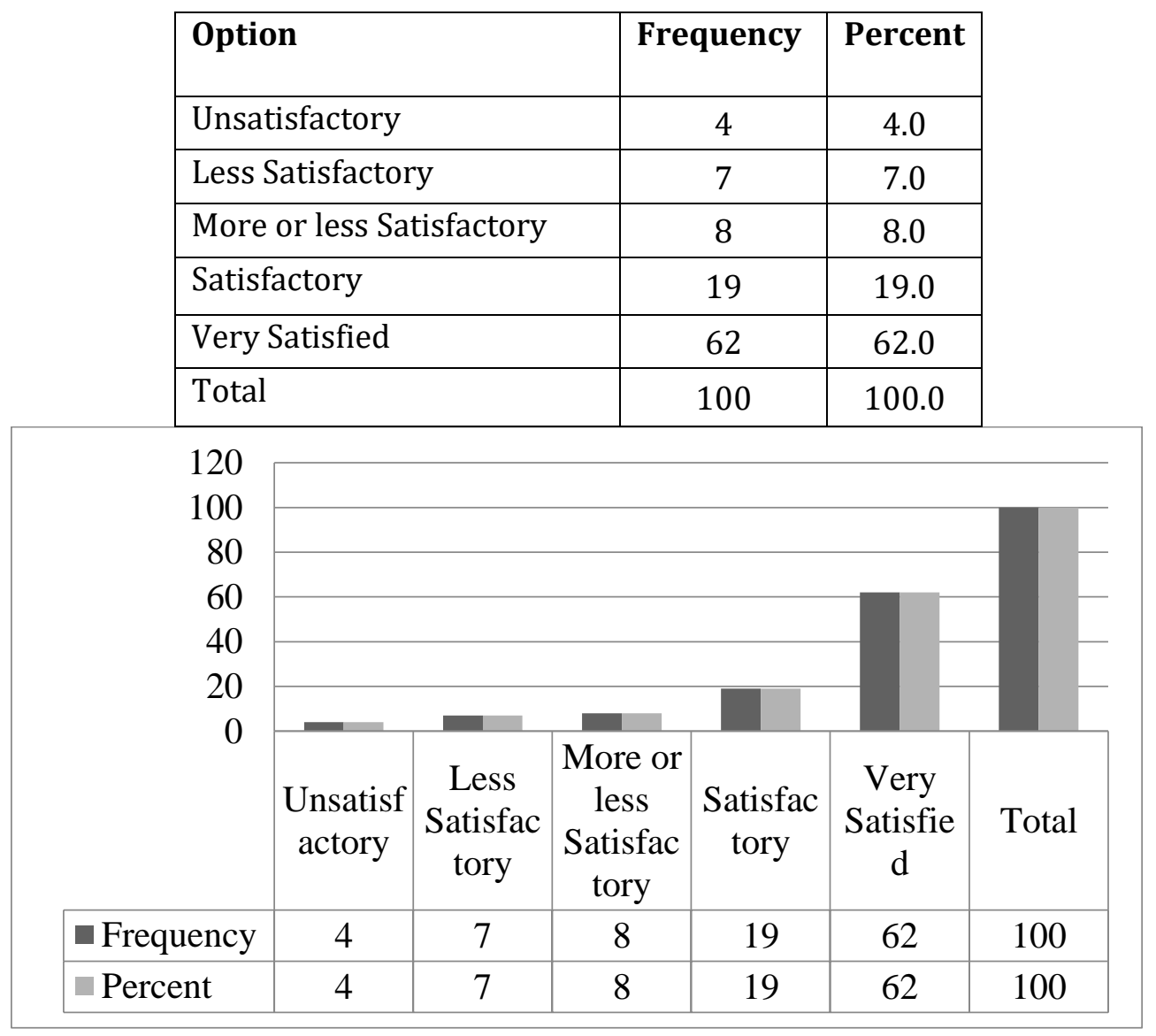


Vol. II, Issue 3, Oct - December 2021

ISSN No: (ONLINE): 2710-043

www.irjei.com
International Research Journal of Education and Innovation ISSN No: ISSN (PRINT): 2710-0448 DOI: https://doi.org/10.53575/irjei.v2.03(21)1.1-14

\section{Satisfaction Level of Athletes Regarding Sports Facilities at Collage Level in Bahawalpur}

Table indicates that $62 \%$ of the respondents very satisfied with statement that I feel that college provided adequate sports equipment athlete. While 19\% satisfied, $8 \%$ more or less satisfactory of respondents $7 \%$ were less satisfactory, and $4 \%$ unsatisfied with the statement.

\section{Table-4.2}

\section{College provides athlete sports tracksuits for competition.}

\begin{tabular}{|l|c|c|}
\hline Option & Frequency & Percent \\
\hline Unsatisfactory & 1 & 1.0 \\
\hline Less Satisfactory & 8 & 8.0 \\
\hline More or less Satisfactory & 12 & 12.0 \\
\hline Satisfactory & 60 & 60.0 \\
\hline Very Satisfied & 19 & 19.0 \\
\hline Total & 100 & 100.0 \\
\hline
\end{tabular}

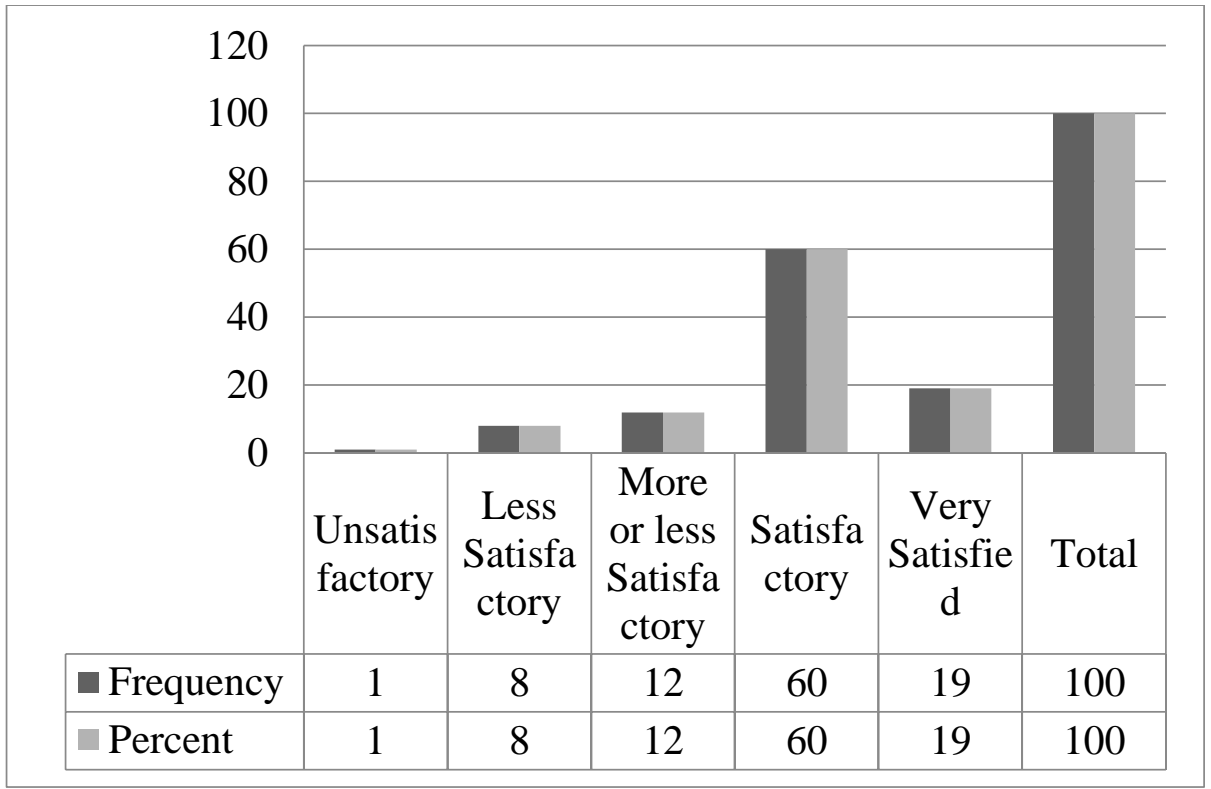

Table indicates that $60 \%$ of the respondents satisfied with statement that I feel that college provided adequate sports equipment athlete. While 19\% very satisfied, 12\% more or less satisfactory of respondents $8 \%$ were less satisfactory, and $1 \%$ unsatisfied with the statement.

\section{Findings, Conclusion \& Recommendations}

\subsection{Findings}

1. $81 \%$ of the respondents very satisfied with statement that I feel that college 


\section{Satisfaction Level of Athletes Regarding Sports Facilities at Collage Level in Bahawalpur}

provided adequate sports equipment athlete.

2. $69 \%$ of the respondents very satisfied with statement that I feel that college provided adequate sports equipment athlete.

3. $75 \%$ of the respondents very satisfied with statement that I feel that college provided adequate sports equipment athlete.

4. $55 \%$ of the respondents very satisfied with statement that My College pays TA/DA during sports competitions.

5. $51 \%$ of the respondents satisfied with statement that My College honored and gives me encouragement in the form of awards and certificates.

6. $70 \%$ of the respondents very satisfied with statement that My College provides reasonable price after winning a competition.

7. $79 \%$ of the respondents very satisfied with statement that My College has a standard court of basketball.

8. $59 \%$ of the respondents satisfied with statement that my college has a gym.

9. $68 \%$ of the respondents very satisfied with statement that My College provides reasonable price after winning a competition.

10. $71 \%$ of the respondents very satisfied with statement that College has a standard ground of football.

11. $75 \%$ of the respondents very satisfied with statement that Sports complex looking beautiful due to its surrounding greenery.

12. $71 \%$ of the respondents very satisfied with statement that College has a proper system for cleanliness of playground.

\subsection{Conclusion}

In a nut shell, majority of respondents are satisfied with adequate sports equipment's provided to athletes and TA/DA giving during sports competitions besides encouragement in the form of awards, certificates, money, etc. Respondents are much impressed with collage's standard basketball court and the availability of gym for physical fitness. Similarly, Football ground is of international standard. Its sports complex is worth seeing owing to lush greenery. Hence, over all collage's atmosphere is clean and conducive for sports man.

\subsection{Recommendations}

1. Need to improve technical coaches for all games.

2. Need to improve sports equipment of national level.

3. Need to sports kits of quality stuff.

4. $\quad$ Need to fitness gym instructor.

5. Increase athletes traveling and daily allowance.

$6 \quad$ Increase demand for fitness classes on male and female athletes.

$7 \quad$ Increase equipment specialized training zones for restricted fitness.

8 From oversize gym to communal health and wellness center

9 One of the keys to better sports facility maintenance planning is to set measurable objectives so that progress during a set period can be monitored.

10 Improvement to the interior of the Science Building

11 Rebuilding of Commercial Street retaining wall 
Vol. II, Issue 3, Oct - December 2021

ISSN No: (ONLINE): 2710-043

www.irjei.com
International Research Journal of Education and Innovation

ISSN No: ISSN (PRINT): 2710-0448

DOI: https://doi.org/10.53575/irjei.v2.03(21)1.1-14

Satisfaction Level of Athletes Regarding Sports Facilities at Collage Level in Bahawalpur

\section{REFERENCES}

1. African American Students: A Pilot Study. Recreational Sports Journal, 33(1). 25-34.

2. Antonio, J. (2011). How construction trends of Universities sport facilities will be affected by financial crisis: A survey. Scientific Research and Essays. 6(9), 1998-2002.

3. Arslan, Dilawar (2010). Research information and recommendations to improve sports facilities in college. Thesis report submitted to the Superior College Lahore.

4. Bargchi, M. (2010). Exploratory research on sports facilities construction in Malaysia. Australian journal of basic and applied sciences. 4 (10), 5326-5331.

5. Bogar, Craig. T. (2012). Trends in Collegiate Recreational Sports Facilities. The sport Journal. Pp.15.

6. Business Management (pp. 425-428). Chengdu. Scientific Research Publication.

7. Dabas, Chandra, Sarkar (1982). The Survey of Facilities and Equipments of Sports in Engineering Colleges in West Bengal Unpublished Master,,s Thesis, Laxmibai National Institute of Physical Education, Jiwaji College, and Gwalior.

8. EKURI, P. K., EDIM, M. E., ODOK, E. A. (2014). Predictive Variables Influencing

9. $\backslash$ Feng X. (2008). Assessing the Economic Impact of Sports Facilities on Residential Property Values: A Spatial Hedonic Approach. North American Association of Sports Economists working paper series 08-12.

10. Hui, Zhou. (2010). Research on relationship between College Sports Facilities and Mass Sports. The Conference on Web Based

11. Ishak, I. S., \& Alias, R. A. (2005). Designing a strategic information system planning methodology for Malaysian institutes of higher learning (ISP-IPTA): University Teknologi Malaysia.

12. Lidor, R., Melnik, Y., Bilkevitz, A., Arnon, M., \& Falk, B. (2005). Measurement of talent in judo using a unique, judo-specific ability test. Journal of Sports Medicine and Physical Fitness, 45(1), 32.

13. Robert, Lindsey (2012). Impact of Campus Recreational Sports Facilities and Programs on Recruitment and Retention Among

14. Sawant, S. (2014). MOOCs as a means of continuing professional development for LIS educators in India.

15. Students Participation in Combative Sports in Nigeria. International Journal of Secondary Education, 2(3), 48-51.

16. Wang, J.-S., LAN, C., \& Wong, M.-K. (2001). Tai Chi Chuan training to enhance microcirculatory function in healthy elderly men. Archives of physical medicine and rehabilitation, 82(9), 1176-1180. 